\title{
HUBUNGAN KONSEP DIRI AKADEMIK DENGAN PRESTASI AKADEMIK
}

\author{
Oleh : \\ Saifullah \\ Fakultas Dakwah IAI Ibrahimy Situbondo \\ Saivul.07@gmail.com
}

\begin{abstract}
Abstact
This study aims to test empirically the relationship between academic self concept and student's academic achievement of SMK "A" Banyuputih. The hypothesis proposed that there is a positive relationship between academic self concept and student's academic achievement. Participants of the study comprised 150 of SMK students. The research data obtained from academic self concept scale and students report. Data analyzed use product moment correlation technique. The results showed that the data obtained correlation values $r x y=0,325$ with $p=0,001$. This is indicate that there was a positive relationship between academic self concept and student's academic achievement significantly.
\end{abstract}

Key Words: Academic Self Concept, Achievement, Confidence, Effort.

\section{A. Pendahuluan}

Pembangunan pendidikan nasional didasarkan pada paradigma pembangunan manusia Indonesia seutuhnya, yang berfungsi sebagai subyek yang memiliki kapasitas untuk mengaktualisasikan potensi dan dimensi kemanusiaan secara optimal dalam menghadapi era globalisasi. Dimensi yang dimaksud dalam hal ini adalah: (1) Afektif merujuk pada kemampuan siswa untuk menginternalisasi nilai-nilai yang diterima sehingga kemudian menjadi bagian dari dirinya dalam membentuk kualitas keimanan dan ketakwaan, etika dan estetika, serta akhlak mulia dan budi pekerti luhur (2) Kognitif yang tercermin pada kapasitas pikir dan daya intelektualitas untuk menggali ilmu pengetahuan dan mengembangkan serta menguasai teknologi, dan (3) Psikomotorik yang tercermin pada kemampuan mengembangkan ketrampilan teknis dan kecakapan praktis. ${ }^{1}$

Paradigma pembangunan pendidikan nasional menempatkan anak didik pada kedudukan yang sangat sentral. Pendidikan merupakan proses

1 Krathwohl, D. R. A Revision of Bloom's Taxonomy: An Overview Theory Into Practice, (2002). Vol. 41, No. 4, hlm. 213-260. 
sistematis untuk meningkatkan martabat manusia secara holistik, yang memungkinkan ketiga dimensi kemanusiaan paling elementer di atas dapat berkembang secara optimal. Dengan demikian, pendidikan dapat berfungsi menjadi wahana strategis untuk mengembangkan segenap potensi diri pembelajar.

Kualitas pendidikan di Indonesia dapat dilihat pada laporan penelitian yang telah dilakukan oleh The World Bank, World Development Report 2007, yang menempatkan posisi Indonesia pada peringkat ke 39 dari 41 negara yang diteliti. ${ }^{2}$ Hal ini menunjukkan bahwa kualitas pendidikan Indonesia tertinggal dengan negara-negara lain. Penyebab rendahnya mutu pendidikan di Indonesia salah satunya disebabkan oleh faktor internal yang berhubungan dengan faktor psikologis individu seperti motivasi, efikasi diri, dan konsep diri. ${ }^{3}$

Pesatnya perkembangan ilmu pengetahuan dan teknologi menyediakan berbagai macam informasi yang secara positif dapat menambah wawasan keilmuan bagi siswa. Interaksi dengan dunia informatika dapat menumbuh kembangkan kemampuan siswa dalam mengorganisir, mengkategorisasi, dan mempertimbangkan berbagai informasi baru untuk diadaptasi. Selanjutnya individu memilih informasi yang diinginkannya dan membuang informasi yang tidak cocok baginya. Dampak lain dari pesatnya perkembangan ilmu pengetahuan dan teknologi adalah menuntut siswa untuk belajar lebih mandiri, lebih mengetahui potensi-potensi (kekuatan dan kelemahan) yang dimilikinya untuk meningkatkan kualitas akademiknya, lebih percaya diri dalam menanggapi lingkungan akademik dan mengembangkan kemampuan akademik. Sejumlah atribut yang melekat pada diri siswa tersebut dibutuhkan untuk menanggapi lingkungan akademik dan mengembangkan kemampuan akademik secara lebih baik. Kepercayaan diri dalam menanggapi lingkungan akademik merupakan salah satu aspek penting dalam memahami konsep diri akademik siswa. ${ }^{4}$

Shevelson dan Bolus, mendefinisikan konsep diri akademik sebagai penilaian diri siswa akan kemampuannya yang mencakup persepsi dan

\footnotetext{
2 The World Bank, World Development Report 2007: Development and the next generation. (2006).

3 Saifullah. Pengaruh Metode 'Learning Together' terhadap Prestasi Pemahaman Bacaan Siswa pada Mata Pelajaran Bahasa Inggris di SMP. (Yogyakarta: Fakultas Psikologi Universitas Gadjah Mada, 2012). Tesis tidak diterbitkan.

${ }^{4}$ Eggen, P., \& Kauchak, D. Educational psychology: Windows on classrooms (8 ${ }^{\text {th }}$ ed.). (New Jersey: Pearson Education, Inc, 2010).
}

$252 \mid$ JURNAL LISAN AL-HAL 
perasaan siswa tentang penerimaan diri, kepercayaan diri, dan penghargaan diri yang berkaitan dengan bidang akademik yang digeluti di sekolah. ${ }^{5}$ Liu, Wang, dan Parkins, mendefinisikan konsep diri akademik sebagai keyakinan akademik dan upaya akademik dalam melakukan tugatugas akademis untuk mencapai prestasi akademik ${ }^{6}$ Konsep diri akademik dapat terbentuk melalui lingkungan sekolah dan secara khusus dipengaruhi oleh penguatan yang diterimanya melalui proses belajar di sekolah.

Siswa mempersepsi kapabilitas dirinya secara totalitas dengan melibatkan berbagai aspek seperti kognitif dan emosi menjadi suatu sikap atau perilaku. Konsep diri akademik merupakan dasar dari prestasi akademik dan perilaku akademik dan menjadi penentu untuk mencapai tujuan belajar yang telah ditetapkan. ${ }^{7}$ Konsep diri akademik berperan penting dalam proses perkembangan individu pada masa belajar yang diharapkan dapat memerankan dirinya sebagai pembelajar di sekolah serta mampu merespon segala bentuk perubahan yang terjadi dalam lingkungannya. ${ }^{8}$

Siswa dengan kepercayaan diri tinggi akan berusaha secara maksimal menggunakan kemampuannya untuk mengerjakan tugas-tugas akademik, siswa dengan komitmennya terlibat aktif dalam setiap proses pembelajaran dan memiliki ketertarikan untuk mengerjakan tugas-tugas akademik baik di dalam ataupun di luar kelas, sehingga hal ini akan berimplikasi pada meningkatnya prestasi akademik siswa. ${ }^{9}$ Siswa dengan konsep diri akademik tinggi akan menunjukan prestasi akademik tinggi, sebaliknya siswa dengan konsep diri akademik rendah cenderung akan menunjukan prestasi akademik yang juga rendah. 10 Siswa yang

5 Shevelson, R. J., \& Bolus, R. Self concept: The interplay of theory and methods. (Journal of Educational Psychology, 1982), Vol. 74, No. 1, hlm. 3-17.

${ }^{6}$ Liu, W. C., Wang, C. J. K., \& Parkins, E. J. A longitudinal study of students' academic self-concept in a streamed setting: The Singapore context. (British Journal of Educational Psychology, 2005), Vol. 75, hlm. 567-586.

7 Skaalvik, E. M., \& Skaalvik, S. Self-Concept And Self-Efficacy In Mathematics: Relation With Mathematics Motivation And Achievement. (Joumal of Education Research, 2009). 3, (3), hlm. 255-278.

${ }^{8}$ Feist, J., dan Feist, G. J. Theories of personality (6 ${ }^{\text {th }}$ ed.). (New York: The McGrow Hill Companies, Inc. 2006)

9 Skaalvik, S \& Skaalvik, E. M. Self-Concept, Motivational Orientation, And HelpSeeking Behavior In Mathematics: A Study Of Adults Returning To High School. (Social Psychology of Education, 2005).Vol. 8, hlm. 285-302, doi: 10.1007/s11218-005-3276-3.

${ }^{10}$ Eggen, P., \& Kauchak, D. Educational psychology: Windows on classrooms (8 $8^{\text {th }}$ ed.). (New Jersey: Pearson Education, Inc. 2010). 
mempunyai konsep diri tinggi akan memandang dirinya secara positif, percaya diri, antusias menetapkan tujuan yang ingin dicapai, terdorong untuk terlibat aktif dalam pembelajaran, sehingga pada akhirnya akan berdampak pada meningkatnya prestasi belajar yang dicapai siswa. ${ }^{11}$

Hasil penelitian tentang hubungan konsep diri akademik dengan prestasi akademik yang telah dilakukan oleh peneliti terdahulu, menemukan bahwa konsep diri akademik secara positif berkorelasi dengan prestasi akademik, siswa dengan konsep diri akademik tinggi akan menunjukkan motivasi dan ketertarikan yang lebih tinggi dalam belajar untuk dapat meningkatkan prestasi akademiknya. ${ }^{12}$

Hasil penelitian lain membuktikan bahwa, konsep diri akademik secara signifikan berhubungan dengan prestasi akademik siswa SMA, siswa yang memiliki konsep diri tinggi lebih berani mengungkapkan pendapatnya, mempunyai keinginan yang kuat untuk berhasil, dan berupaya untuk menunjukkan performansi yang baik dalam mengerjakan tugas-tugas akademik. ${ }^{13}$ Konsep diri akademik yang dimaksud pada penelitian ini adalah persepsi, perasaan (keyakinan akademik), komitmen, keterlibatan, dan ketertarikan (upaya akademik) untuk mencapai prestasi akademik di sekolah. Berdasar uraian yang telah dipaparkan, peneliti mengajukan hipotesi penelitian, yaitu ada hubungan positif antara konsep diri akademik dengan prestasi akdemik siswa.

Penentuan variabel tergantung pada penelitian ini adalah prestasi akademik, sedangkan variabel bebasnya adalah konsep diri akademik. Subyek penelitian adalah seluruh siswa SMK "A" di Banyuputih Situbondo sebanyak 150 orang siswa. Pemilihan subjek dalam penelitian ini menggunakan teknik sampel purposif dengan memperhatikan karakteristik yang dimiliki oleh subyek penelitian.

Cara pengumpulan data dalam penelitian ini adalah menggunakan skala likert untuk konsep diri akademik. Skala konsep diri akademik mengadaptasi konstruk yang dikembangkan oleh Liu, dkk, yaitu skala

${ }^{11}$ Woolfolk, A. Educational psychology active learning edition (10 ${ }^{\text {th }}$ ed.). (Boston: Pearson Education, Inc. 2008).

12 Yahaya, A., Ramli, J., Boon, Y., Ghaffar, M. N. A., \& Zakariya, Z. Relationship between Self Concepts and Personality and Students' Academic Performance in Selected Secondary School.( European Journal of Social Sciences, 2009), Vol.11, No. 2, hlm. 302316.

13 Yara, P. O. Students' Self-Concept and Mathematics Achievement in some Secondary Schools In Southwestern Nigeria. (European Journal of Social Sciences, 2010), Vol. 13,No. 1, hlm. 127-132.

254 JURNAL LISAN AL-HAL 
Academic Self-Concept (ASC) yang terdiri dari 19 aitem dengan konsistensi internal alpha Cronbach $(\alpha)$ 0,83. ${ }^{14}$ Skala ASC dapat mengungkap aspekaspek konsep diri akademik siswa seperti aspek percaya diri siswa terhadap kemampuan akademiknya dan aspek komitmen siswa untuk terlibat dan tertarik dalam tugas-tugas akademik di sekolah. Selain menggunakan skala, penelitian ini juga menggunakan dokumentasi nilai rapot semester ganjil tahun pelajaran 2013 / 2014 untuk memperoleh data. Jumlah nilai tersebut kemudian dijadikan acuan untuk menetapkan variabel prestasi akademik. Teknik analisis data yang digunakan dalam penelitian ini adalah menggunakan analisis korelasi Product Moment dari Pearson untuk menguji hubungan antara konsep diri akademik dengan prestasi akademik.

\section{B. Hasil Penelitian}

Sebelum dilakukan analisis, terlebih dahulu dilakukan uji normalitas sebaran data untuk kedua variabel. Hasilnya adalah, skor variabel konsep diri akademik berdistribusi normal $\left(\mathrm{Z}_{\mathrm{K}-\mathrm{s}}=1,056\right.$ dengan $\mathrm{p}$ $=0,215)$ dan variabel prestasi akademik berdistribusi normal $\left(\mathrm{Z}_{\mathrm{K}-\mathrm{s}}=0,787\right.$ dengan $p=0,565$ ).

Uji linieritas hubungan dilakukan untuk mengetahui linieritas hubungan antara variabel bebas dan variabel terikat atau untuk mengetahui taraf penyimpangan dari linieritas hubungan tersebut. Hasilnya adalah hubungan variabel konsep diri akademik dengan prestasi akademik linier $(\mathrm{F}=17,698$ dengan $\mathrm{p}=0,001$ dan nilai deviation from linierity sebesar 1,021). Hasil uji hipotesis menunjukkan bahwa ada hubungan yang positif dan signifikan antara konsep diri akademik dengan prestasi akademik ( $\mathrm{rxy}=0,325$ dengan $\mathrm{p}=0,001$ ).

\section{Pembahasan}

Hasil penelitian ini memperkuat teori dan hasil penelitian terdahulu, bahwa konsep diri akademik secara positif dan signifikan berhubungan dengan prestasi akademik. Temuan-temuan penelitian penelitian yang dilakukan oleh Liu, ${ }^{15}$ Green, Nelson, Martin, dan Marsh, ${ }^{16}$

14 Liu, W. C., Wang, C. J. K., \& Parkins, E. J. A Longitudinal Study of Students' Academic Self-Concept in a Streamed Setting: The Singapore Context. (British Journal of Educational Psychology, 2005), Vol. 75, hlm. 567-586.

${ }^{15} \mathrm{Liu}, \mathrm{H}$. J. Exploring Changes In Academic Self-Concept In Ability-Grouped English Classes. (Chang Gung Journal of Humanities and Social Sciences, 2009), Vol. 2, No. 2, hlm. 411-432.

${ }^{16}$ Green, J., Nelson, G., Martin, A.J., dan Marsh, The Causal Ordering Of Self-Concept \begin{tabular}{l|l} 
JURNAL LISAN AL-HAL & 255
\end{tabular} 
Rana dan Iqbal, ${ }^{17}$ Guay, Marsh, \& Boivin, ${ }^{18}$ dan Sanchez dan Roda, ${ }^{19}$ menunjukan bahwa konsep diri akademik secara signifikan dapat meningkatkan prestasi akademik siswa pada semua mata pelajaran dari semua jenjang kelas. Banyak hasil penelitian yang telah didokumentasikan, meliputi siswa yang mempunyai konsep diri tinggi akan memandang dirinya secara positif, lebih percaya diri, antusias menetapkan tujuan yang ingin dicapai, terdorong untuk terlibat aktif dalam pembelajaran, cenderung tidak takut untuk gagal, lebih berani untuk mencoba, optimis, dan selalu mengambil banyak kesempatan untuk meraih kesuksesan dalam belajar.

Konsep diri akademik adalah percaya diri siswa terhadap kemampuan akademiknya dan komitmen untuk terlibat dan tertarik dalam tugas-tugas akademik. Individu yang yakin bahwa dia merasa percaya diri dalam melaksanakan tugas-tugas sekolah dan tumbuh motivasi dan ketertarikan yang lebih tinggi dalam belajar untuk dapat meningkatkan prestasi akademiknya.

Schunk, menyatakan, bahwa konsep diri akademik terbentuk pada saat individu mulai terlibat dengan bidang-bidang akademik atau pada saat individu memasuki bangku sekolah, orangtua, teman sebaya, dan guru. ${ }^{20}$ Lingkungan sekolah memberikan pengembangan ketrampilanketrampilan yang baru yang menjadikan siswa mengevaluasi dirinya dengan cara membandingkan dirinya dengan orang lain dan mempersepsikan evaluasi orang lain terhadap dirinya. Selanjutnya dikatakan bahwa sikap, pengharapan dan evaluasi guru sangat berpengaruh terhadap konsep diri akademik siswa. ${ }^{21}$

And Academic Motivation And Its Effect On Academic Achievement. (International Education Journal, 2006), Vol. 7, hlm. 534-546.

17 Rana, R. A., \& Iqbal, M. Z. Effect Of Students' Self-Concept And Gender On Academic Achievement In Science. (Bulletin of Education \& Research, 2005), Vol. 27, No. 2, hlm. 1936.

18 Guay, F., Marsh, H. W., \& Boivin, M. Academic Self-Concept And Academic Achievement: Developmental Perspectives On Their Causal Ordering. (Journal of Educational Psychology, 2003), Vol. 95, No. 1, hlm. 124-136.

${ }^{19}$ Sanchez, F. J. P., \& Roda, M. D. S. Relationships Between Self-Concept And Academic Achievement In Primary Students. (Electronic Journal of Research in Educational Psychology and Psychopedagogy, 2003), Vol. 1, No.1, hlm. 95-120. ISSN: 1696-2095.

${ }^{20}$ Schunk, D. H. Learning theories: an educational perspective ( $5^{\text {th }}$ ed.). (New Jersey: Pearson Education, Inc, 2008).

21 Ibid.

256 JURNAL LISAN AL-HAL 
Menurut Mars, konsep diri akademik yang positif merupakan variabel yang menunjang performansi akademik, ${ }^{22}$ dan menurut Shevelson \& Bolus, mempunyai peranan yang sangat penting dalam kelangsungan pendidikan siswa ${ }^{23}$ sebagai salah satu tugas perkembangannya sebagai seorang remaja. ${ }^{24}$ Para siswa yang terdiri dari anak usia remaja membutuhkan adanya pengakuan dan penghargaan dari lingkungan. Siswa yang mempunyai konsep diri akan menerima diri sendiri apa adanya mempunyai harapan yang realistik dan kepercayaan diri yang tinggi. Ormrod, menyatakan bahwa konsep diri yang positif dapat diketahui dengan adanya self esteem (penghargaan diri) yang tinggi, sebaliknya konsep diri yang negatif dapat diketahui dengan evaluasi diri yang negatif, rasa benci terhadap diri, merasa rendah diri, kurang dapat menerima dan merasa kurang berharga. ${ }^{25}$ Gambaran yang positif tentang kemampuan diri siswa dalam proses pembelajaran dan persepsinya tetang pandangan guru dan teman-teman sekelas terhadap siswa tersebut akan membentuk konsep diri akademik secara positif maupun secara negatif, konsep diri akademik yang positif ditandai dengan tingginya kepercayaan diri, penerimaan diri, dan penghargaan diri yang menimbulkan perasaan optimis pada diri mahasiswa sehingga akan mempengaruhi keberhasilan belajarnya. Sebaliknya konsep diri akademik yang negatif ditandai dengan rendahnya kepercayaan diri, penerimaan diri, dan penghargaan diri yang menimbulkan perasaan pesimis pada diri siswa sehingga akan menghambat keberhasilan belajarnya.

\section{Kesimpulan}

Hasil penelitian ini dapat disimpulkan ada hubungan positif yang sangat signifikan antara konsep diri akademik dengan prestasi akademik pada siwa SMK 'A" di Banyuputih. Semakin tinggi konsep diri akademik siswa akan semakin baik prestasi akademik siswa, demikian juga sebaliknya semakin rendah konsep diri akademik siswa akan semakin rendah pula prestasi akademik siswa yang dicapainya.

Berdasar hasil temuan ini, siswa diharapkan mampu

22 Marsh, H. W. The Structure Of Academic Self-Concept: The Marsh / Shavelson Model. (Journal or Educational Psychology, 1990)., Vol. 82, No. 4, hlm. 623-636.

23 Shevelson, R. J., \& Bolus, R. Self concept: The interplay of theory and methods. (Journal of Educational Psychology, 1982). Vol. 74, No. 1, hlm. 3-17.

${ }^{24}$ Santrock, J. W. Life-span development (Perkembangan masa hidup), Edisi Kelima Alih bahasa oleh Juda Damanik dan Achmad Chusairi. Jakarta: Penerbit Erlangga, 2008).

${ }^{25}$ Ormrod, J. E. Educational psychology: developing learners ( $4^{\text {th }}$ ed.). (New Jersey: Pearson Education, Inc, 2003). 
mempertahankan dan meningkatkan / mengembangkan konsep diri akademiknya guna kelanjutan pendidikan di masa yang akan datang. Bagi peneliti selanjutnya, perlu diperhatikan variable-variabel lain yang dapat mempengaruhi peningkatan prestasi akademik siswa, seperti; prior knowledge, intelegensi, dan dukungan sosial.

\section{DAFTAR PUSTAKA}

Ahmed, W., \& Bruinsma, M. a Structural Model of Self-Concept, Autonomous Motivation and Academic Performance in Cross-Cultural Perspective. Electronic Research in Educational Psychology. Vol. 10, No. 3. 2006.

Bong, M., \& Skaalvik, E. M. Academic Self-Concept and Self-Efficacy: How Different are They Really?. Educational Psychology Review. Vol. 15, No.1. 2003.

Eggen, P., \& Kauchak, D. Educational psychology: Windows on classrooms ( $8^{\text {th }}$ ed.). New Jersey: Pearson Education, Inc. 2010.

Feist, J., dan Feist, G. J. Theories of personality (6 $6^{\text {th }}$ ed.). New York: The McGrow Hill Companies, Inc. 2006.

Green, J., Nelson, G., Martin, A.J., dan Marsh, The Causal Ordering of SelfConcept and Academic Motivation and Its Effect on Academic Achievement. International Education Journal. Vol. 7. 2006.

Guay, F., Marsh, H. W., \& Boivin, M. Academic Self-Concept And Academic Achievement: Developmental Perspectives On Their Causal Ordering. Journal of Educational Psychology. Vol. 95, No.1. 2003.

Krathwohl, D. R. A Revision of Bloom's Taxonomy: An Overview. Theory Into Practice. Vol. 41, No. 4. 2002, diterima dari http://coe.ohiostate.edu/. tanggal 25 Mei 2011.

Liu, H. J. Exploring Changes In Academic Self-Concept In Ability-Grouped English Classes. Chang Gung Journal of Humanities and Social Sciences. Vol. 2. No. 2. 2009.

Liu, W. C., \& Wang, C. K. J. Academic Self-Concept: A Cross-Sectional Study Of Grade And Gender Differences In A Singapore Secondary School. Asia Pacific Education Review, Vol. 6, No.1. 2005.

Liu, W. C., Wang, C. J. K., \& Parkins, E. J. A longitudinal study of students' academic self-concept in a streamed setting: The Singapore context. British Journal of Educational Psychology, Vol. 75. 2005.Marsh, H. W. Self-Belief Does Make A Differences: A Reciprocal Effect Of The Causal Ordering Of Phsycal Self-Concept And Gymnastic Performance. Journal of Sport Sciences, Vol. 24, No.1. 2006.

$258 \mid$ JURNAL LISAN AL-HAL 
Marsh, H. W. A Reciprocal Effects Model of The Causal Ordering of Academic Self-Concept and Achievement. Self-Concept Enhancement and Learning Facilitation Research Centre. Australia: University of Western Sydney. 2003.

Marsh, H. W. The structure of academic self-concept: The Marsh / Shavelson model. Journal or Educational Psychology, Vol. 82, No. 4. 1990.

Ormrod, J. E. Educational Psychology: Developing Learners (4th ed.). New Jersey: Pearson Education, Inc. 2003.

Rana, R. A., \& Iqbal, M. Z. Effect of Students' Self-Concept and Gender on Academic Achievement in Science. Bulletin of Education \& Research, Vol. 27, No. 2. 2005.

Sanchez, F. J. P., \& Roda, M. D. S. Relationships Between Self-Concept and Academic Achievement In Primary Students. Electronic Journal of Research in Educational Psychology and Psychopedagogy, Vol. 1, No. 1. ISSN: 1696-2095. 2003.

Santrock, J. W. Life-Span Development (Perkembangan Masa Hidup). (Edisi Kelima). Alih bahasa oleh Juda Damanik dan Achmad Chusairi. Jakarta: Penerbit Erlangga. 2008.

Schunk, D. H. Learning theories: an educational perspective ( $5^{\text {th }}$ ed.). New Jersey: Pearson Education, Inc. 2008.

Shevelson, R. J., \& Bolus, R. Self concept: The interplay of theory and methods. Journal of Educational Psychology. Vol. 74, No. 1. 1982.

Skaalvik, E. M., \& Skaalvik, S Self-Concept and Self-Efficacy In Mathematics: Relation With Mathematics Motivation And Achievement. Joumal of Education Research, Vol. 3, No. 3. 2009.

Skaalvik, S \& Skaalvik, E. M. Self-Concept, Motivational Orientation, And Help-Seeking Behavior In Mathematics: A Study Of Adults Returning To High School. Social Psychology of Education, Vol. 8. doi: 10.1007/s11218-005-3276-3. 2005.

Woolfolk, A. Educational psychology active learning edition $\left(10^{\text {th }}\right.$ ed.). Boston: Pearson Education, Inc. 2008.

Yahaya, A., Ramli, J., Boon, Y., Ghaffar, M. N. A., \& Zakariya, Z. Relationship between Self Concepts and Personality and Students' Academic Performance in Selected Secondary School. European Journal of Social Sciences, Vol. 11, No. 2. 2009.

Yara, P. O. Students' Self-Concept and Mathematics Achievement In Some Secondary Schools In Southwestern Nigeria. European Journal of Social Sciences, Vo. 13, No. 1. 2010. 
"Hubungan Konsep Diri \& Akademik"

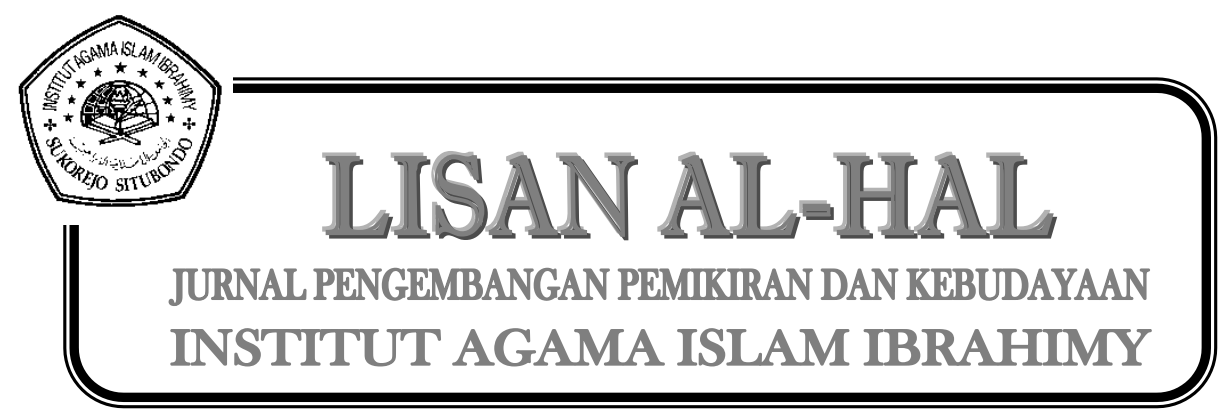

$260 \mid$ JURNAL LISAN AL-HAL 
